\title{
If phosphatidylserine is the death knell, a new phosphatidylserine-specific receptor is the bellringer
}

\author{
VA Fadok $^{*, 1}$, D Xue ${ }^{2}$ and P Henson ${ }^{1}$ \\ ${ }^{1}$ Program in Cell Biology, Department of Pediatrics, National Jewish Medical \\ and Research Center, Denver, Colorado, C0 80206, USA \\ 2 Molecular, Cellular, and Developmental Biology, University of Colorado, \\ Boulder, Colorado, CO, USA \\ * Corresponding author: VA Fadok, National Jewish Medical and Research \\ Center, D509, 1400 Jackson Street, Denver, Colorado, C0 80206, USA. \\ Tel: 1-303-398-1281; Fax: 1-303-398-1381; E-mail: fadokv@njc.org
}

Received 25.10.00; revised 8.2.01; accepted 19.2.01

Edited by M Piacentini

\begin{abstract}
Recognition of phosphatidylserine (PtdSer) is essential for engulfment of apoptotic cells by mammalian phagocytes. Engagement of a new phosphatidylserine-specific receptor (PtdSerR) appears to be necessary for uptake of apoptotic cells. Many other mammalian receptors have been described to function in the clearance of apoptotic cells. The emerging picture is that many of these receptors may provide the strong adhesion needed to increase the likelihood of contact between the PtdSerR and its phospholipid ligand, which is required for uptake. Furthermore, stimulation of this receptor on different types of phagocytes by apoptotic cells, PtdSer-containing liposomes or an IgM monoclonal anti-PtdSer antibody initiates release of $\operatorname{TGF} \beta$, known to be involved in the anti-inflammatory effects of apoptotic cells. Although highly homologous genes exist in C. elegans and Drosophila melanogaster, their role in engulfment of apoptotic cells remains to be determined. Cell Death and Differentiation (2001) 8, 582-587.
\end{abstract}

Keywords: phagocytosis; apoptosis; phosphatidylserine; receptor; cytokines

Abbreviations: $\beta 2 \mathrm{GPI}$, beta 2 glycoprotein 1 ; BMDM, bone marrow-derived macrophages; HMDM, human monocyte-derived macrophages; LDL, low density lipoprotein; PAF, platelet activating factor; PGE2, prostaglandin E2; POP-L-PS, 1-palmitoyl-2-oleoylsn-3 glycerophospho-L-serine; POP-D-PS, 1-palmitoyl-2-oleoylsn-3 glycerophospho-D-serine; PtdSer, phosphatidylserine; PtdSerR, phosphatidylserine receptor; TGF $\beta$, transforming growth factor-beta

In order for phagocytes, including macrophages, to recognize and engulf them, apoptotic cells must lose phospholipid asymmetry and expose phosphatidylserine on the outer leaflet of the plasma membrane. ${ }^{1}$ Learning how macrophages and other phagocytes recognize this phospholipid has been a crusade for our laboratories and those of many other investigators. Many different types of receptors have been implicated in the uptake of apoptotic cells. An emerging pattern is that many of the same recognition receptors responsible for recognizing and engulfing pathogens also mediate recognition and engulfment of apoptotic cells, yet the outcome is very different. These include lectins, Class A and Class B scavenger receptors, CD68 and other receptors for oxidized LDL particles, CD14, selected integrins, C1q and collectin binding proteins, complement binding proteins, and $\beta 2 \mathrm{GPI}$ binding proteins. ${ }^{2-22}$ Uptake of apoptotic cells appears to be anti-inflammatory and possibly even immunosuppressive, at least with regard to self antigens. For example, it was recently shown that only necrotic tumor cells, but not apoptotic cells, could drive dendritic cell maturation and subsequent activation of T lymphocytes. ${ }^{23}$ In contrast, uptake of pathogens is proinflammatory and promotes an adaptive immune response. Understanding this conundrum is an important goal for investigators studying the clearance of apoptotic cells by phagocytes.

\section{A brief history of the quest for a phosphatidylserine-specific receptor}

We have recently cloned the gene for a novel protein that appears to mediate specific recognition of phosphatidylserine on apoptotic cells by phagocytes and is highly conserved throughout phylogeny. ${ }^{24}$ It was first reported as a gene of unknown function cloned from a human brain library; however, the authors made the observation that the gene was highly homologous to an undescribed gene from Caenorhabditis elegans contained on cosmid F2929. ${ }^{25}$ A highly homologous gene is also found in the genome of Drosophila melanogaster, its function in this organism is also unknown. For lack of a better name, since it does not fall into any of the known receptor families, we have called this protein the phosphatidylserine-specific receptor (PtdSerR). ${ }^{24}$

The PtdSerR is expressed on macrophages, fibroblasts, endothelial cells, epithelial cells, melanoma cells (Fadok, unpublished data), and human dendritic cells (Fadok, unpublished data); in short, on virtually all the cells described to mediate clearance of apoptotic bodies ${ }^{24}$ It is not expressed on the surface of circulating cells such as lymphocytes, neutrophils, monocytes, or red blood cells. On macrophages, expression is variable. The expression on human monocyte-derived macrophages or mouse bone marrow-derived macrophages is low, unless they are stimulated with digestible particles such as $\beta$-glucan, zymosan, or even apoptotic cells themselves. ${ }^{24}$ In contrast, thioglycollate-elicited peritoneal macrophages express high surface levels of this receptor, which 
correlates with their ability to recognize apoptotic cells in a PtdSer-inhibitable manner. The human cDNA, when transfected into human Jurkat $T$ cells and mouse M12.C3 B lymphocytes (two undisputedly nonphagocytic cell lines) enabled them to bind to and engulf apoptotic cells and PtdSer-expressing red blood cells. ${ }^{24}$

Several years ago we proposed the hypothesis that the ability to recognize PtdSer by macrophages was dependent on the macrophage subpopulation used. ${ }^{26,27}$ These observations were based on whether uptake of apoptotic cells could be inhibited by PtdSer-containing liposomes or not. Based on our current data and those of others, we believe it is time to dispel this notion. It has become clear that all macrophages, and in fact, all phagocytes, recognize phosphatidylserine on apoptotic cells. Our earlier misinterpretation arose from the fact that inhibition assays, particularly when using liposomes, are relatively insensitive in determining how a macrophage recognizes apoptotic cells. Insensitive though they are, inhibition assays were all we knew to use in the infancy of the study of clearance. Savill and coworkers had originally reported that human monocyte-derived macrophages (HMDM) could recognize apoptotic cells using a complex of receptors, the $\alpha \mathrm{v} \beta 3$ vitronectin receptor and CD36, which were bridged to the apoptotic cells by thrombospondin. ${ }^{7,8}$ Uptake by these cells, as well as by mouse bone marrow-derived macrophages (BMDM), was inhibited by the tetrapeptide RGDS and antibodies against $\alpha \mathrm{v} \beta 3$ or CD36, but not by PtdSercontaining liposomes. ${ }^{26,28}$ In contrast, HMDM or BMDM treated with TGF $\beta$ and $\beta$-glucan lost their ability to be inhibited by the $\alpha \mathrm{v} \beta 3$ antibodies, and acquired the ability to be inhibited by PtdSer-containing liposomes. ${ }^{26,28}$ Pradham and coworkers, however, later went on to demonstrate that while uptake of apoptotic cells by BMDM was not inhibited by PtdSer-containing liposomes, it could be inhibited by PtdSer-expressing symmetric red blood cells. ${ }^{29}$ They also observed that pretreatment with annexin V, PtdSer binding protein, could inhibit uptake of apoptotic cells by all macrophages studied. ${ }^{30,31}$

Recently, we reported that apoptotic cells which failed to express phosphatidylserine externally were not engulfed by either macrophages (stimulated or not to upregulate the PtdSerR) or fibroblasts. ${ }^{1}$ Restoration of PtdSer in the outer leaflet by liposome transfer or by differentiating the cells prior to induction of apoptosis restored recognition and uptake by either type of macrophage or by fibroblasts. Furthermore, only $L$ stereoisomers were effective; 1palmitoyl-2-oleoyl-sn-3 glycerophospho-L-serine (POP-LPS) but not POP-D-PS was able to signal the phagocyte for uptake, and inhibition was inhibited by the monoclonal anti-PtdSerR antibody. All the data at this point, therefore, are most consistent with the hypothesis that phosphatidylserine on apoptotic cells must be engaged by the PtdSerR on phagocytes before engulfment can proceed.

\section{Distribution, structure, and function of the mammalian PtdSer receptor}

The gene for the PtdSer-specific receptor encodes a type II protein of approximately $48 \mathrm{kd}$. A simple bar structure of the protein is shown in Figure 1. There are multiple serines in the predicted extracellular domain which appear to be glycoslyated, as deglycosylation reduces the apparent molecular weight in Western blots from approximately 70 to $48 \mathrm{kd}^{24}$ There is at least one potential tyrosine phosphorylation site in the predicted intracellular domain. There are runs of basic residues in the extracellular domain, which could provide a binding site for the negatively charged phosphoserine head group of PtdSer. In addition, there is a weak WW domain as well; this domain has been implicated in the binding of phosphoserine and phosphotyrosine residues in proteins. It, therefore, could provide a potential binding site for phosphoserine in a phospholipid. ${ }^{32}$ This protein does not contain the proposed consensus binding sequence for phosphatidylserine (FxFxLKxxxKxR) found in protein kinase C isoforms, phospholipase $\mathrm{C}$, and phosphatidylserine decarboxylase. ${ }^{33}$ Nor does it have any sequence similarities to the annexins, coagulation factors, vitronectin, or complement proteins known to bind to PtdSer. ${ }^{34-38}$

As mentioned before, we have observed the PtdSerR on many different types of cells which engulf apoptotic bodies, including macrophages, fibroblasts, epithelial cells, and endothelial cells. ${ }^{24}$ Staining with the monoclonal antiPtdSerR antibody on unfixed and nonpermeabilized cells has shown that the distribution of the PtdSer-specific receptor on the surface of fibroblasts, macrophages, and epithelial cells appears to be punctate rather than diffusely distributed around the membrane; other cell types remain to be tested. There are two possible explanations for this distribution which are currently being explored. First, the PtdSerR is associated with specific membrane lipid domains, such as caveolae or rafts; this remains to be explored but preliminary evidence obtained from mammary epithelial cells suggests that caveolin-1, a marker for caveolae, does not colocalize with the PtdSerR. Second, it is possible that PtdSer-containing vesicular debris from ongoing cell death in the cell cultures is continually crosslinking this receptor on the phagocyte surface. Figure 2 shows a fibroblast which has engulfed fluorescently-labeled apoptotic cells. In this case, the phagocytes were fixed prior to staining, to show that the PtdSerR clusters around the engulfed apoptotic bodies. With regard to tissue distribution, using RT-PCR, we have preliminary evidence that the gene is expressed in multiple tissues and organs, and as early as day 7 of embryogenesis in the mouse (unpublished data). This tissue expression pattern is consistent with our observation that the receptor is present on many different cell types.

Using a novel biotinylated red cell system, we have created particles for uptake which will trigger single receptors using specific antibodies or natural ligands (Hoffman P, Fadok VA, Henson PM, unpublished data). The red blood cells are biotinylated; biotinylated antibodies are then attached via a streptavidin bridge. Antibodies against human CD36, $\alpha \mathrm{v} \beta 3$, CD68, CD14, or mouse SRA promoted binding but not uptake of these particles; antiCD36, in particular, appeared to promote very strong binding. The red cells were only engulfed, however, if their outer plasma membranes had been reconstituted with phosphatidyl-L-serine; phosphatidyl-D-serine was not effec- 


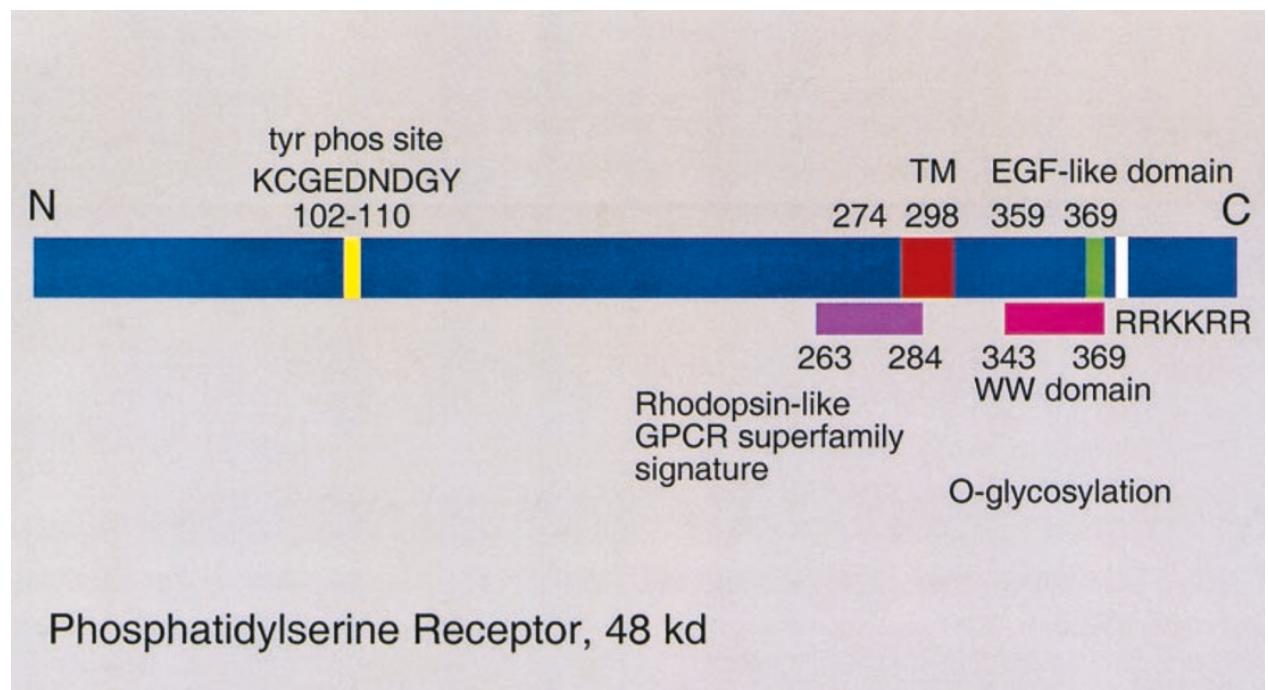

Figure 1 Bar diagram of the phosphatidylserine receptor, which is predicted to be a type II protein. The extracellular domain contains a weak motif for a WW domain which could represent a possible binding site for phosphoserine (see text). Alternatively, the run of basic residues (RRKKRR) could bind to the anionic head group of PtdSer. There is a potential tyrosine phosphorylation and multiple potential PKC phosphorylation site (not shown) in the predicted intracellular domain, which could provide signaling capabilities. TM=transmembrane domain. The significance of the rhodopsin GPCR-like motif and the EGF-like motif is not known at this time

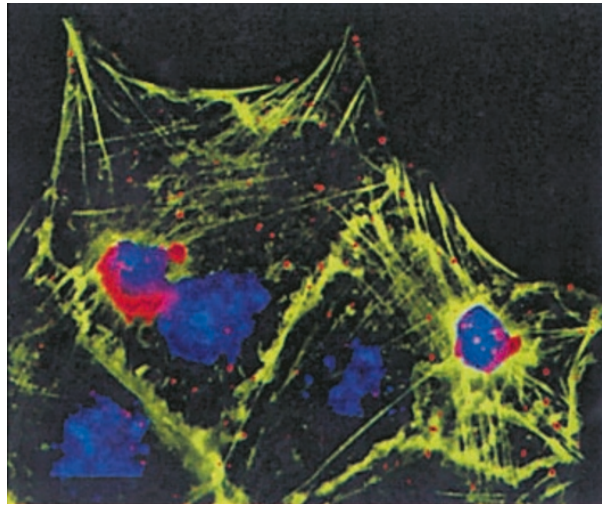

Figure 2 Phosphatidylserine receptor clusters around apoptotic bodies during engulfment. NIH3T3 cells were exposed to apoptotic Jurkat T cells, then fixed and permeabilized briefly with $4 \%$ paraformaldehyde in sucrose. The cells were stained with Alexa 488-conjugated phalloidin (Molecular Probes, Eugene, OR, USA) to show actin, with DAPI to identify the nuclei of the phagocytes and the apoptotic bodies, and with mAb 217G8E9 followed by Cy3-labeled anti-mouse IgM (Jackson Immunoresearch Laboratories, Inc. West Grove, PA, USA). Apoptotic Jurkat T cells have very little cytoplasm, accounting for the apparent antibody staining around their nuclei

tive. Uptake was then inhibited by anti-PtdSerR antibody. As an alternative, NIH3T3 cells were transfected with vector containing the sense or antisense sequence of the PtdSer receptor. The antisense construct significantly reduced expression of the PtdSer receptor and significantly inhibited uptake of apoptotic cells (see Figure 3). Taken together, these data suggest that many of the receptors involved in apoptotic cell recognition promote strong adhesion, but that the PtdSer receptor must be engaged for engulfment to occur.

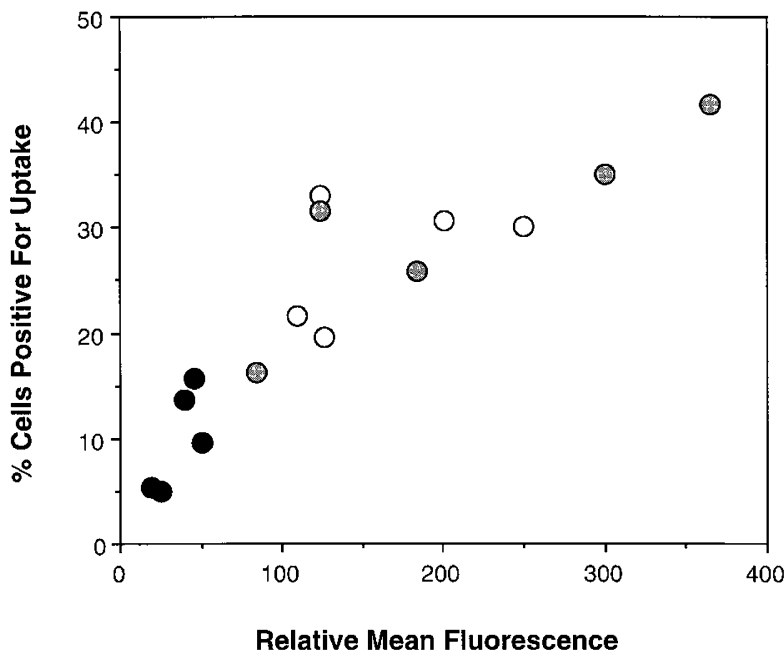

Figure 3 Expression levels of the PtdSerR is correlated with ability to take up apoptotic cells $\left(n=5 ; r^{2}=0.78 ; P<0.0001\right)$. Expression of the PtdSerR was reduced by transfecting $\mathrm{NIH} 3 \mathrm{~T} 3$ cells transiently with pcDNA3.1 containing the reverse sequence of the entire PtdSerR, and assessing uptake of apoptotic Jurkat $\mathrm{T}$ cells $18 \mathrm{~h}$ later. Expression of the PtdSerR was assessed by flow cytometry, and levels are shown as the relative mean fluorescence ( $x$-axis). Uptake is expressed as per cent cells positive for uptake ( $y$-axis). The black circles represent those cells transfected with the antisense construct; the grey circles represent those cells that were mock transfected; the open circles represent those cells transfected with empty vector. Note that loss of PtdSerR expression is associated with reduced ability to take up apoptotic cells

\section{The anti-inflammatory properties of the phosphatidylserine receptor}

Exposure to apoptotic cells is found to be not only noninflammatory, ${ }^{49-51}$ but actively anti-inflammatory. ${ }^{52-54}$ By 
inducing the release of TGF $\beta$ and PGE2, apoptotic cells caused downregulation of chemokines, TNF $\alpha, \operatorname{IL} 1 \beta$, and IL10 from endotoxin-stimulated macrophages, as anti-TGF $\beta$ antibodies, indomethacin, and a platelet-activating factor receptor antagonist restored production of these cytokines. $^{52}$ Exposure of mouse macrophages (J774 cells) to apoptotic cells also resulted in the release of $\operatorname{TGF} \beta$ and reduction in proinflammatory cytokines. ${ }^{53}$ These effects could be mimicked by treatment with PtdSer-containing liposomes, as well as by $\mathrm{mAb} 217$, suggesting that the interaction of phosphatidylserine on the apoptotic cells with this receptor on the phagocyte caused the release of anti-inflammatory mediators. ${ }^{24}$ This interpretation receives further support from two of our preliminary observations: first, that the fibroblasts transfected with anti-sense constructs for PtdSerR not only fail to engulf apoptotic cells but also fail to produce TGF $\beta$, and second, that apoptotic cells which fail to express phosphatidylserine externally fail to induce TGF $\beta$ secretion.

\section{Does the PtdSerR play a role in engulfment of apoptotic cells in invertebrates?}

The role of this gene product in engulfment of apoptotic cells by phagocytes from other organisms remains to be determined. It is intriguing to note that there is high homology between the mammalian receptor and the genes of unknown function in Drosophila melanogaster and C. elegans. To date, the role of this gene is being actively studied in both these organisms. The notion that this gene would function in engulfment of apoptotic cells in nonmammalian organisms is appealing, as phosphatidylserine, at least with regard to its polar head group, is not polymorphic. This phospholipid is found in the plasma membranes of all eukaryotic cells. Exposure of phosphatidylserine in the membranes of Drosophila cells undergoing apoptosis has been convincingly demonstrated by van den Eijnde and colleagues, ${ }^{55}$ and it seems likely that worm cells would also undergo loss of phospholipid asymmetry, although this remains to be proven.

The study of cell corpse engulfment in $C$. elegans has revealed a wealth of information on the genes used by viable cells to recognize and engulf their dying neighbors, and it is encouraging to note that many similar genes are involved in mammalian recognition and engulfment. ${ }^{56-60}$ Pairing the genetic and molecular studies in C. elegans and Drosophila melanogaster with the mammalian functional studies has proved to be a powerful tool, as illustrated by the characterization of ced-7 and one of its human homologs the ABC1 transporter, ${ }^{58,61-63}$ ced-6 and its human homolog, ${ }^{56,57,64,65}$ and ced-2, ced-5, and ced-10 with CRKII, DOCK 180, and Rac-1 $1^{60,66-69}$ and fly croquemort and its human homolog CD36..$^{8,70,71}$ Furthermore, the identity of ced-1 has recently been reported and the protein appears to be a surface receptor for recognition of apoptotic cells with homology to mammalian scavenger receptors. ${ }^{72}$

\section{The future of the PtdSer-specific receptor}

The PtdSer receptor we have identified will provide years of interesting work for us and hopefully others. There are many questions to be asked and answered. Our preliminary observations that this protein is expressed in intracellular membranes suggests a role in addition to recognition of apoptotic cells. It is possible that the PtdSerR could be important in intracellular phosphatidylserine transport, although it has no homologs in yeast as far as we have been able to determine and this is only speculation. How the protein recognizes phosphatidylserine and what accounts for the stereospecificity remains to be determined. It is unknown whether glycosylation is important for this function, or for some other function. The presence of charged residues within the predicted transmembrane domain suggests the potential for interaction with other proteins within the membrane, and the presence of cysteines in the extracellular domain suggest this protein may function as an oligomer, rather than a monomer.

What is clear at this point is that the PtdSer receptor binding to phosphatidylserine on the apoptotic cell is necessary for uptake of apoptotic cells and release of anti-inflammatory mediators. This PtdSer receptor is widespread, with regard to phylogeny, embryogenesis, tissue distribution, and cell type and is therefore likely to play a central role in clearance of apoptotic cells.

\section{References}

1. Fadok VA, de Cathelineau A, Daleke DL, Henson PM and Bratton DL (2001) Loss of phospholipid asymmetry and surface exposure of phosphatidylserine is required for phagocytosis of apoptotic cells by macrophages and fibroblasts. J. Biol. Chem. 276: 1071-1077

2. Dini L, Autuori F, Lentini A, Oliverio S and Piacentini M (1992) The clearance of apoptotic cells in the liver is mediated by the asialoglycoprotein receptor. FEBS Lett. 296: $174-178$

3. Dini L, Lentini A, Diez GD, Rocha M, Falasca L, Serafino L and Vidal-Vanaclocha F (1995) Phagocytosis of apoptotic bodies by liver endothelial cells. J. Cell. Sci. 108: $967-973$

4. Dini L (1998) Endothelial liver cell recognition of apoptotic peripheral blood lymphocytes. Biochem. Soc. Trans. 26: 635-639

5. Duvall E, Wyllie AH and Morris RG (1985) Macrophage recognition of cells undergoing programmed cell death (apoptosis). Immunology 56: 351-358

6. Falasca L, Bergamini A, Serafino A, Balabaud Cand Dini L (1996) Human Kupffer cell recognition and phagocytosis of apoptotic peripheral blood lymphocytes. Exp. Cell. Res. 224: 152-162

7. Savill J, Dransfield I, Hogg N and Haslett C (1990) Vitronectin receptor-mediated phagocytosis of cells undergoing apoptosis. Nature 343: 170-173

8. Savill J, Hogg N and Haslett C (1991) Macrophage vitronectin receptor, CD36, and thrombospondin cooperate in recognition of neutrophils undergoing programmed cell death. Chest 99: $6 S-7 S$

9. Shiratsuchi A, Umeda M, Ohba Y and Nakanishi Y (1997) Recognition of phosphatidylserine on the surface of apoptotic spermatogenic cells and subsequent phagocytosis by Sertoli cells of the rat. J. Biol. Chem. 272: 23542358

10. Shiratsuchi A, Kawasaki Y, Ikemoto M, Arai $H$ and Nakanishi $Y$ (1999) Role of class $B$ scavenger receptor type I in phagocytosis of apoptotic rat spermatogenic cells by Sertoli cells. J. Biol. Chem. 274: 5901-5908

11. PlattN, Suzuki H, Kurihara Y, Kodama T and Gordon S (1996) Role for the class A macrophage scavenger receptor in the phagocytosis of apoptotic thymocytes in vitro. Proc. Natl. Acad. Sci. USA 93: 12456-12460

12. Sambrano GR and Steinberg D (1995) Recognition of oxidatively damaged and apoptotic cells by an oxidized low density lipoprotein receptor on mouse peritoneal macrophages: role of membrane phosphatidylserine. Proc. Natl. Acad. Sci. USA 92: 1396-1400

13. Sambrano GR, Terpstra V and Steinberg D (1997) Independent mechanisms for macrophage binding and macrophage phagocytosis of damaged erythrocytes. Evidence of receptor cooperativity. Arterioscler. Thromb. Vasc. Biol. 17:34423448 
14. Oka K, Sawamura T, Kikuta K, Itokawa S, Kume N, Kita T and Masaki T (1998) Lectin-like oxidized low-density lipoprotein receptor 1 mediates phagocytosis of aged/apoptotic cells in endothelial cells. Proc. Natl. Acad. Sci. USA 95: $9535-$ 9540

15. Devitt A, Moffatt OD, Rakundalia C, Capra JD, Simmons DL and Gregory CD (1998) Human CD14 mediates recognition and phagocytosis of apoptotic cells. Nature 392: 505-509

16. Flora PK and Gregory CD (1994) Recognition of apoptotic cells by human macrophages: inhibition by a monocyte/macrophage-specific monoclonal antibody. Eur. J. Immunol. 24: 2625-2632

17. Mevorach D, Mascarenhas JO, Gershov D and Elkon KB (1998) Complementdependent clearance of apoptotic cells by human macrophages. J. Exp. Med. 188: $2313-2320$

18. Schwartz BR, Karsan A, Bombeli T and Harlan JM (1999) A novel beta 1 integrindependent mechanism of leukocyte adherence to apoptotic cells. J. Immunol. 162: $4842-4848$

19. Taylor PR, Carugati A, Fadok VA, Cook HT, Andrews M, Carroll MC, Savill JS Henson PM, Botto M and Walport MJ (2000) A hierarchical role for classica pathway complement proteins in the clearance of apoptotic cells in vivo. J. Exp. Med. 192: 359-366

20. Botto M, Dell'Agnola C, Bygrave AE, Thompson EM, Cook HT, Petry F, Loos M, Pandolfi PP and Walport MJ (1998) Homozygous C1q deficiency causes glomerulonephritis associated with multiple apoptotic bodies [see comments] Nat. Genet. 19: 56-59

21. Balasubramanian K, Chandra J and Schroit AJ (1997) Immune clearance of phosphatidylserine-expressing cells by phagocytes. The role of beta2glycoprotein I in macrophage recognition. J. Biol. Chem. 272: 31113-31117

22. Balasubramanian K and Schroit AJ (1998) Characterization of phosphatidylserine-dependent beta2-glycoprotein I macrophage interactions. Implications for apoptotic cell clearance by phagocytes. J. Biol. Chem. 273: 29272-29277

23. SauterB, AlbertML, Francisco L, Larsson M, Somersan Sand Bhardwaj N (2000) Consequences of cell death: exposure to necrotic tumor cells, but not primary tissue cells or apoptotic cells, induces the maturation of immunostimulatory dendritic cells [see comments]. J. Exp. Med. 191: 423-434

24. Fadok VA, Bratton DL, Rose DM, Pearson A, Ezekowitz RA and Henson PM (2000) A receptor for phosphatidylserine-specific clearance of apoptotic cells [see comments]. Nature 405: 85-90

25. Nagase T, Ishikawa K-I, Miyajima N, Tanaka A, Kotani H, Nomura N and Ohara $\mathrm{O}$ (1998) Prediction of the coding sequences of unidentified human genes. IX. The complete sequences of 100 new cDNA clones from brain which can code for large proteins in vitro. DNA Res. 5: 31-39

26. Fadok VA, Savill JS, Haslett C, Bratton DL, Doherty DE, Campbell PA and Henson PM (1992) Different populations of macrophages use either the vitronectin receptor or the phosphatidylserine receptor to recognize and remove apoptotic cells. J. Immunol. 149: 4029-4035

27. Fadok VA, Laszlo DJ, Noble PW, Weinstein L, Riches DW and Henson PM (1993) Particle digestibility is required for induction of the phosphatidylserine recognition mechanism used by murine macrophages to phagocytose apoptotic cells. J. Immunol. 151: 4274-4285

28. Fadok VA, Warner ML, Bratton DL and Henson PM (1998) CD36 is required for phagocytosis of apoptotic cells by human macrophages that use either a phosphatidylserine receptor or the vitronectin receptor (alpha $v$ beta 3 ). J. Immunol. 161: 6250-6257

29. Pradhan D, Krahling S, Williamson P and Schlegel RA (1997) Multiple systems for recognition of apoptotic lymphocytes by macrophages. Mol. Biol. Cell. 8 : $767-778$

30. Krahling S, Callahan MK, Williamson P and Schlegel RA. (1999) Exposure of phosphatidylserine is a general feature in the phagocytosis of apoptotic lymphocytes by macrophages. Cell Death Differ. 6: 183-189

31. Callahan MK, Williamson P and Schlegel RA. (2000) Surface expression of phosphatidylserine on macrophages is required for phagocytosis of apoptotic thymocytes. Cell Death Differ. 7: 645-653

32. Lu PJ, Zhou XZ, Shen M and Lu KP (1999) Function of WW domains as phosphoserine- or phosphothreonine-binding modules. Science 283: 13251328.
33. Igarashi K, Kaneda M, Yarnaji A, Saido TC, Kikkawa U, Ono Y, Inoue K and Umeda M (1995) A novel phosphatidylserine binding peptide motif defined by an anti-idiotypic monoclonal antibody. Localization of phosphatidylserine-specific binding sites on protein kinase $\mathrm{C}$ and phosphatidylserine decarboxylase. J. Biol. Chem. 270: 29075-29078

34. Tait J, Sakata M, McMullen BA, Miao CH, Funakoshi T, Hendrickson LE and Fujikawa K (1988) Placental anticoagulant proteins: isolation and comparative characterization four members of the lipocortin family. Biochemistry 27: 62686276

35. Funakoshi T, Hendrickson LE, McMullen BA and Fujikawa K (1987) Primary structure of human placental anticoagulant protein. Biochemistry 26: 80878092

36. Funakoshi T, Heimark RL, Hendrickson LE, McMullen BA and Fujikawa K (1987) Human placental anticoagulant protein: isolation and characterization. Biochemistry 26: $5572-5578$

37. Andree HA, Stuart MC, Hermens WT, Reutelingsperger CP, Hemker HC, Frederick PM and Willems GM (1992) Clustering of lipid-bound annexin V may explain its anticoagulant effect. J. Biol. Chem. 267: 17907-17912

38. Andree HA, Reutelingsperger CP, Hauptmann R, Hemker HC, Hermens WT and Willems GM (1990) Binding of vascular anticoagulant alpha (VAC alpha) to planar phospholipid bilayers. J. Biol. Chem. 265: 4923-4928

39. Reutelingsperger CP, Hornstra G and Hemker HC (1985) Isolation and partial purification of a novel anticoagulant from arteries of human umbilical cord. Eur. J. Biochem. 151: 625-629

40. TaitJF and Gibson D (1992) Phospholipid binding of annexin V: effects of calcium and membrane phosphatidylserine content. Arch. Biochem. Biophys. 298: 187191

41. Tait JF and Gibson D (1990) Interaction of placental anticoagulant protein-I (lipocortin V) with model membranes. Prog. Clin. Biol. Res. 349: 173-181

42. Tait JF, Gibson D and Fujikawa K (1989) Phospholipid binding properties of human placental anticoagulant protein-I, a member of the lipocortin family. J. Biol. Chem. 264: 7944-7949

43. Zwaal RFA (1978) Membrane and lipid involvement in blood coagulation. Biochim. Biophys. Acta 515: 163-205

44. Liu C, Marshall P, Schreibman I, Vu A, Gai W and Whitlow M (1999) Interaction between terminal complement proteins $\mathrm{C} 5 \mathrm{~b}-7$ and anionic phospholipids. Blood 93: $2297-2301$

45. Yoneda A, Ogawa H, Kojima K and Matsumoto I (1998) Characterization of the ligand binding activities of vitronectin: interaction of vitronectin with lipids and identification of the binding domains for various ligands using recombinant domains. Biochemistry 37: 6351-6360

46. Test ST and Mitsuyoshi J (1997) Activation of the alternative pathway of complement by calcium-loaded erythrocytes resulting from loss of membrane phospholipid asymmetry. J. Lab. Clin. Med. 130: 169-182

47. Liu D, Liu F and Song YK (1995) Recognition and clearance of liposomes containing phosphatidylserine are mediated by serum opsonin. Biochim. Biophys. Acta 1235: 140-146

48. Wang RH, Phillips G, Medof ME and Mold C (1993) Activation of the alternative complement pathway by exposure of phosphatidylethanolamine and phosphatidylserine on erythrocytes from sickle cell disease patients. J. Clin. Invest. 92: 1326-1335

49. Meagher LC, Savill JS, Baker A, Fuller RW and Haslett C (1992) Phagocytosis of apoptotic neutrophils does not induce macrophage release of thromboxane B2. J. Leukoc. Biol. 52: 269-273

50. Stern M, Savill J and Haslett C (1996) Human monocyte-derived macrophage phagocytosis of senescent eosinophils undergoing apoptosis. Mediation by alpha $v$ beta $3 / C D 36 /$ thrombospondin recognition mechanism and lack of phlogistic response. Am. J. Pathol. 149: 911-921

51. Hughes J, Liu Y, Van Damme J and Savill J (1997) Human glomerular mesangial cell phagocytosis of apoptotic neutrophils: mediation by a novel CD36independent vitronectin receptor/thrombospondin recognition that is uncoupled from chemokine secretion. J. Immunol. 158: 4389-4397 
52. Fadok VA, Bratton DL, Konowal A, Freed PW, Westcott JY and Henson PM (1998) Macrophages that have ingested apoptotic cells in vitro inhibit proinflammatory cytokine production through autocrine/paracrine mechanisms involving TGF-beta, PGE2, and PAF. J. Clin. Invest. 101: 890-898

53. McDonald PP, Fadok VA, Bratton DL and Henson PM (1999) Transcriptional and translational regulation of inflammatory mediator production by endogenous TGFb in macrophages that have ingested apoptotic cells. J. Immunol. (in press)

54. Voll RE, Herrmann M, Roth EA, Stach C, Kalden JR and Girkontaite I (1997) Immunosuppressive effects of apoptotic cells [letter]. Nature 390: 350-351

55. van den Eijnde SM, Boshart L, Baehrecke EH, De Zeeuw Cl, Reutelingsperger CPM and Vermeij-Keers C (1998) Phosphatidylserine exposure by apoptotic cells is phylogenetically conserved. Apoptosis 3: $9-16$

56. Liu QA and Hengartner MO (1998) Candidate adaptor protein CED-6 promotes the engulfment of apoptotic cells in C. elegans. Cell 93: 961-972

57. Liu QA and Hengartner MO (1999) Human CED-6 encodes a functional homologue of the Caenorhabditis elegans engulfment protein CED-6. Curr. Biol. 9: $1347-1350$

58. Wu YC and Horvitz HR (1998) The C. elegans cell corpse engulfment gene ced-7 encodes a protein similar to ABC transporters. Cell 93: 951-960

59. Wu YC and Horvitz HRC (1998) C. elegans phagocytosis and cell-migration protein CED-5 is similar to human DOCK 180 [see comments]. Nature 392:501504

60. Reddien PW and Horvitz HR (2000) CED-2/Crkll and CED-10/Rac control phagocytosis and cell migration in Caenorhabditis elegans. Nat. Cell. Biol. 2: $131-136$

61. Hamon Y, Broccardo C, Chambenoit O, Luciani MF, Toti F, Chaslin S, Freyssinet JM, Devaux PF, McNeish J, Marguet D and Chimini G (2000) ABC1 promotes engulfment of apoptotic cells and transbilayer redistribution of phosphatidylserine. Nat. Cell. Biol. 2: 399-406

62. Marguet D, Luciani MF, Moynault A, Williamson P and Chimini G (1999) Engulfment of apoptotic cells involves the redistribution of membrane phosphatidylserine on phagocyte and prey. Nat. Cell. Biol. 1: 454-456
63. Luciani MF and Chimini G (1996) The ATP binding cassette transporter ABC1, is required for the engulfment of corpses generated by apoptotic cell death. EMBO J. $15: 226-235$

64. Su HP, Brugnera E, Van Criekinge W, Smits E, Hengartner M, Bogaert T and Ravichandran KS (2000) Identification and characterization of a dimerization domain in CED-6, an adapter protein involved in engulfment of apoptotic cells. J. Biol. Chem. 275: 9542-9549

65. Smits E, Van Criekinge W, Plaetinck G and Bogaert T (1999) The human homologue of Caenorhabditis elegans CED- 6 specifically promotes phagocytosis of apoptotic cells. Curr. Biol. 9: 1351-1354

66. Albert ML, Kim JI and Birge RB (2000) alphavbeta5 integrin recruits the CrkllDock180-rac1 complex for phagocytosis of apoptotic cells. Nat. Cell. Biol. 2: $899-905$

67. Liu QA and Hengartner MO (1999) The molecular mechanism of programmed cell death in C. elegans. Ann. NY Acad. Sci. 887: 92-104

68. Driscoll M (1996) Cell death in C. elegans: molecular insights into mechanisms conserved between nematodes and mammals. Brain Pathol. 6: 411-425

69. Ellis RE, Jacobson DM and Horvitz HR (1991) Genes required for the engulfment of cell corpses during programmed cell death in Caenorhabditis elegans. Genetics 129: 79-94

70. Franc NC, Dimarcq JL, Lagueux M, Hoffmann J and Ezekowitz RA (1996) Croquemort, a novel Drosophila hemocyte/macrophage receptor that recognizes apoptotic cells. Immunity 4: $431-443$

71. Franc NC, Heitzler P, Ezekowitz RA and White K (1999) Requirement for croquemortin phagocytosis of apoptotic cells in Drosophila. Science 284: 1991 1994

72. Zhou Z, Hartwieg E and Hrovitz HR (2001) CED-1 is a transmembrane receptor that mediates cell corpse engulfment in C. elegans. Cell 104: 43-56 